\title{
Evaluation of Bactericidal Action of 2-vinylpiridine Copolymers Containing Quaternary Ammonium Groups and Their Charge Transfer Complexes
}

\author{
Aline S. S. Valle, Mônica R. C. Marques, Luciana C. Costa , Luiz C. Santa Maria \\ Departamento de Química Orgânica, Instituto de Química, Universidade do Estado do Rio de Janeiro, UERJ \\ Alcino Palermo de Aguiar \\ Departamento de Engenharia Química, Instituto Militar de Engenharia, IME \\ Fábio Merçon \\ Departamento de Processos Químicos, Instituto de Química, Universidade do Estado do Rio de Janeiro, UERJ
}

\begin{abstract}
We report the development of copolymers based on 2-vinylpyridine with different porosity degrees. The copolymers were quaternized with methyl iodide and acrylonitrile to introduce quaternary ammonium groups on pyridine units. To prepare charge transfer complexes, the unmodified copolymers and their derivatives quaternized were impregnated with iodine. The antibacterial properties of all the polymers were evaluated ranging from of the Escherichia coli strain. The unmodified copolymers did not have antibacterial activity against E.Coli suspensions. The quaternization with methyl iodine and acrylonitrile increased the biocidal performance of these copolymers, but only the copolymer with the lowest porosity modified with methyl iodine showed significant bactericidal action for all $E$. Coli concentrations. The 2-vinylpiridine copolymers quaternized and impregnated with iodine had higher antibacterial activity than the impregnated ones. The charge transfer complexes derived from the copolymer with the lowest porosity and highest swelling capacity in water had the best bactericidal performance.
\end{abstract}

Keywords: Porous materials, 2-vinylpiridine copolymers, quaternary ammonium groups, charge transfer complexes, biocidal.

\section{Introduction}

Various types of biocidal polymers have been prepared and studied for water treatment. Disinfection using biocidal polymers has several advantages over ozone and many soluble disinfectants. The main advantage is the possibility of inactivating or destroying microorganisms present in contaminated water without leaving behind residues that can yield halomethane analogues. Many of these halomethane analogues are suspected of being carcinogenic $^{[1-3]}$.

Biocidal polymers can be classified into two categories, according to the bactericidal mechanism: insoluble polymeric contact disinfectants and demand-release disinfectants ${ }^{[4]}$. For contact disinfectants, the disinfecting action is attributed to contact phenomena which disrupt the cell membranes of bacteria, resulting in leakage of essential intracellular constituents. In contrast, demand-release disinfectants work through controlled release of the active compound in the medium. Thus, complete bactericidal sterilization of highly contaminated water can be achieved without introducing appreciable amounts of the biocidal residues into the water, thus avoiding the formation of halomethane analogues.

The preparation of a biocidal polymer usually consists of the incorporation of a bactericidal group into a previously synthesized polymer matrix. Two methods can be used for this purpose: impregnation of the antibacterial agent on the polymeric support or chemical modification of the polymer ${ }^{[1-10]}$. Alternatively, monomers containing the bactericidal groups can be polymerized and subsequently cross-linked to obtain a biocidal polymer ${ }^{[0,11-13]}$. Although polymerization of functionalized monomers is a more direct route to prepare biocidal polymers, these functionalized monomers are expensive and it is hard to obtain spherical beads with controlled morphology.
Styrene-divinylbenzene (Sty-DVB) copolymers have been extensively used as supports for biocidal groups ${ }^{[2,4-8]}$ These materials are mainly prepared by free-radical crosslinking copolymerization of styrene (Sty) and divinylbenzene (DVB) in the presence of an initiator and a diluent. It has been established that the porosity degree and the pore size distribution of the beads are determined by diluent nature, dilution degree of the monomers and crosslinker concentration. The main factor influencing the copolymer morphological structure is the diluent type used in synthesis. In general, when the diluent is a good solvent of the growing polymer chains, these chains remain solvated during the polymerization period, resulting in the formation of a gel material. On the other hand, if a nonsolvent is used as diluent, the phase separation occurs before the gel point, forming a porous structure $^{[14-18]}$.

The efficiency of a biocidal polymer is determined by the nature of its bactericidal group and the morphological characteristics of the polymer matrix. The porous structure and swelling properties of the polymer support influence the process of reagent diffusion and consequently the extent of modification reactions for introducing the functional groups in this matrix, as well as the accessibility of those introduced groups by bacteria or the diffusion of the biocidal agent in the medium ${ }^{[7,8]}$.

Iodine shows a strong tendency to form charge transfer complexes even with weak electron donors. Pyridine reacts with iodine to form a stable molecular $n-\sigma$ complex $^{[7,8]}$. In our last work, we verified that charge transfer complexes prepared from 2-vinylpiridine copolymers possess antibacterial activity against E.Coli suspensions ${ }^{[19]}$. The objective of this work is to investigate the biocidal activity of $2 \mathrm{Vpy}-\mathrm{Sty}-\mathrm{DVB}$ copolymers containing

Corresponding author: Mônica R. C. Marques, Departamento de Química Orgânica, Instituto de Química, Universidade do Estado do Rio de Janeiro - UERJ, Rua São Francisco Xavier 524, Maracanã, CEP 20559-900, Rio de Janeiro, RJ, Brazil, e-mail: monicamarques@uerj.br 
different quaternary ammonium groups and their charge transfer complexes impregnated with iodine and to establish the relationship between the morphological characteristics of copolymers supports and the biocidal activity of the resultant materials.

\section{Experimental Part}

\section{Chemicals}

Commercial styrene (Sty), divinylbenzene (DVB) and 2-vinylpiridine (2Vpy) were donated by Nitriflex Indústria e Comércio S.A. (Rio de Janeiro, Brazil) and were used as received. 2,2-azo-bis(2-methylbutanonitrile-Vaso 67) and 2-hydroxyethylcellulose were donated by Metacril (Rio de Janeiro, Brazil) and Union Carbide (New Jersey, USA) respectively, and used also as received. Other reagents and solvents were purchased from Vetec Química Fina Ltda. (Rio de Janeiro, Brazil) and used as received. Agar, tryptone and yeast extract of Bacto ${ }^{\mathrm{TM}}$ grade for use in microbiological culture media were purchased from Himedia Laboratories PVT Limited (Mumbai, India). The auxotopic E. Coli OHd5-K-12 strain was obtained from P. Howard-Flanders (Yale University, New Haven, CT).

\section{Preparation of 2Vpy-Sty-DVB copolymer}

2Vpy-Sty-DVB copolymers were synthesized by aqueous suspension polymerization in a $1 \mathrm{~L}$ three-necked round bottomed reactor flask equipped with a mechanical stirrer and a reflux condenser containing a silicon oil seal at the top. The aqueous phase, composed of $\mathrm{Na}_{3} \mathrm{PO}_{4}(16.95 \mathrm{~g})$ to diminish the monomer solubility in water, along with gelatin $(1.7 \mathrm{~g})$ and 2-hydroxiethylcellulose $(1.7 \mathrm{~g})$ as suspension agents, was prepared and transferred to the flask. The organic phase, consisting of $2 \mathrm{Vpy}(36.8 \mathrm{~mL}, 70 \%$ in relation to total of mols of monomers), Sty $(5.7 \mathrm{~mL}, 10 \%$ in relation to total of mols of monomers), DVB (14 mL, $10 \%$ in relation to total of mols of monomers), AIBN (1.08 g, 5.10-3 mol in relation to total mols of monomers) and a diluent mixture composed of two different toluene/n-heptane ratios (70/30 and 50/50 v/v in relation to total volume of diluent mixture), was prepared and also transferred to the flask already containing the aqueous phase. The volumetric ratio between the diluent mixture and monomer mixture was $1: 1$ $(\mathrm{v} / \mathrm{v})$. Thus, the volumes of toluene and n-heptane were $39.5 \mathrm{~mL}$ and $17 \mathrm{~mL}$ respectively. The volumetric ratio between the aqueous and organic phase was 5:1 (v/v). Therefore, the volume of water was $282.5 \mathrm{~mL}$. The composition of the diluent mixture was varied with the aim of producing two copolymers with different porosity degrees. These two copolymers were designated C30Hep and C50Hep, respectively, according to proportion of the n-heptane in the diluent mixture. The system was stirred continuously (400 rpm) at $70{ }^{\circ} \mathrm{C}$ for 24 hours. The beads obtained were washed several times with hot water $\left(70{ }^{\circ} \mathrm{C}, 6\right.$ portions of $\left.500 \mathrm{~mL}\right)$ and acetone $(250 \mathrm{~mL})$ in a Soxhlet extractor (reflux temperature, 24 hours) and finally dried at atmospheric pressure for $48 \mathrm{~h}$ at $60{ }^{\circ} \mathrm{C}^{[19]}$.

\section{Quaternization reaction of 2Vpy-Sty-DVB copolymers with methyl iodide}

The dried 2Vpy-Sty-DVB copolymers $(6.0 \mathrm{~g})$ were swelled in methanol $(40 \mathrm{~mL})$ for 12 hours to favor the diffusion of the reagent solution through the interior of the polymer matrix. Methyl iodide ( $3.5 \mathrm{~mol}$ ) was added to the flask containing swollen beads and the reaction mixture was refluxed for 24 hours. The product thus formed was filtered, washed several times with hot water $\left(70{ }^{\circ} \mathrm{C}, 500 \mathrm{~mL}\right)$ and acetone $(250 \mathrm{~mL})$ and then dried at atmospheric pressure for 24 hours at $60{ }^{\circ} \mathrm{C}^{[19]}$.

\section{Quaternization of 2Vpy-Sty-DVB copolymers with acrylonitrile}

Firstly, the copolymer beads $(6.0 \mathrm{~g})$ were swelled in methanol $(40 \mathrm{~mL})$ for 12 hours. An ethanolic solution of $\mathrm{HCl}\left(1 \mathrm{~mol} \mathrm{~L}^{-1}\right)$ and acrylonitrile $(5.95 \mathrm{~mol})$ was added and the resulting mixture was refluxed for 3 days. The beads were filtered, washed with hot water $\left(70{ }^{\circ} \mathrm{C}, 500 \mathrm{~mL}\right)$ and acetone $(250 \mathrm{~mL})$ and dried at atmospheric pressure for 24 hours at $60{ }^{\circ} \mathrm{C}^{[20]}$.

\section{Preparation of polymeric charge transfer complexes}

The unmodified and quaternized copolymers were impregnated with iodine according to the method established by Jandrey et al. using two different methods: solvent phase and vapor phase ${ }^{[7,8,19]}$ :

- Solvent phase (i1): $1.0 \mathrm{~g}$ of copolymer was weighed in the flask and $25 \mathrm{~mL}$ of methanol and $2.3 \mathrm{~g}$ of $\mathrm{I}_{2}$ were added. The system was kept under stirring at $200 \mathrm{rpm}$ at $27^{\circ} \mathrm{C}$ during 72 hours;

- Vapor phase (i2): $1 \mathrm{~g}$ of the copolymer was kept in contact with $2.3 \mathrm{~g}$ of ground solid iodine in a closed flask at $27^{\circ} \mathrm{C}$ for 3 hours.

After reaction with iodine, the polymers were washed several times with water (4 portions of $250 \mathrm{~mL}$ ) and dried at atmospheric pressure for 24 hours at $60{ }^{\circ} \mathrm{C}$.

\section{Characterization of 2Vpy-Sty-DVB copolymers}

The 2Vpy-Sty-DVB copolymers was characterized by determining apparent density by the graduated cylinder method, ${ }^{[21]}$ surface area and pore volume distribution by nitrogen adsorption measurements, following the BET and $\mathrm{BJH}$ methods respectively (Micromeritcs, ASAP 2010 apparatus). The polymers appearance was observed under an optical microscope (Olympus SZ10, magnification: $\times 50$ ). Their shape and surface texture were monitored with a JEOL-JSM 6460 LV scanning electron microscope operating at $20 \mathrm{keV}$, magnification: $\times 5000$. For SEM, the samples were spread on a conductive tape and sputtered with gold.

The degree of swelling (DS) in methanol and water was determined using a graduated cylinder $(10 \pm 0.1 \mathrm{~mL})$, which was filled with about $3 \mathrm{~mL}$ of dry polymer. The solvent was added up to the $10 \mathrm{~mL}$ level and 24 hours later the final volume was read. The DS was calculated according to Equation $1^{[19]}$ :

$$
\operatorname{DS}(\%)=(\mathrm{Vf}-\mathrm{Vi}) / \mathrm{Vi}
$$

where: $\mathrm{Vi}=$ volume of the dry polymer $(\mathrm{mL})$ and $\mathrm{Vf}=$ volume of the polymer after swelling for 24 hours $(\mathrm{mL})$.

Elemental analysis of polymers was performed in a PerkinElmer CHNS/O Analyzer (2400 Series II), applying dynamic flash combustion for sample analysis.

FTIR spectra of polymers in the form of $\mathrm{KBr}$ pellets were obtained using a Perkin-Elmer (Spectrum One) spectrometer (4 scans and $4 \mathrm{~cm}^{-1}$ resolution). The iodine incorporation degree on polymeric charge transfer complexes was determined by gravimetry ${ }^{[22]}$.

\section{Antibacterial testing}

The antibacterial activity of the polymers was determined against E. Coli cells (E. Coli OHd5-K-12) as previously described ${ }^{[7,8,19]}$. Columns containing the polymers were prepared by using $1.0 \mathrm{~mL}$ sterilized syringes with about $200 \mathrm{mg}$ of sample. $1500 \mu \mathrm{L}$ of a sterile $\mathrm{NaCl}$ aqueous solution $(0.9 \% \mathrm{w} / \mathrm{v})$ was eluted through all columns. The same volume of saline solutions containing $E$. coli at varying concentrations $\left(10^{3}, 10^{4}, 10^{5}, 10^{6}\right.$, and $10^{7}$ cells $\left.\mathrm{mL}^{-1}\right)$ was successively eluted through the columns. After elution through the bead bed, the bacterial suspensions were appropriately diluted in saline to obtain a suspension containing about $2 \times 10^{3}$ cells $\mathrm{mL}^{-1}$. 
Suitable $100 \mu \mathrm{L}$ aliquots of these suspensions were plated on LB nutrient medium solidified with $1.5 \%$ Bacto agar. The colonies formed (CFU) were counted after incubation for 24 hours at 37 ${ }^{\circ} \mathrm{C}$. The bactericidal activity of the polymers was estimated by calculating the decrease in the number of bacteria, according to Equation $2^{[7]}$. Triplicates of independent experiments were carried out.

$$
\text { Action }=100 \times\left(\mathrm{CFU}_{\mathrm{i}}-\mathrm{CFU}_{\mathrm{f}}\right) / \mathrm{CFU}_{\mathrm{i}}
$$

where $=\mathrm{CFU}_{\mathrm{i}}$ : colonies formed before elution through the polymers and $\mathrm{CFU}_{\mathrm{f}}=$ colonies formed after elution through the polymers.

Stability tests: $450 \mu \mathrm{L}$ of sterile saline solutions was eluted through of the columns containing about $200 \mathrm{mg}$ of sample, and then $50 \mu \mathrm{L}$ of E. Coli $10^{4}$ cells $\mathrm{mL}^{-1}$ was added to the eluted volume. After 3 minutes of contact, $100 \mu \mathrm{L}$ aliquots of these solutions were plated on solidified LB nutrient medium. The colonies formed (CFU) were counted after incubation for 24 hours at $37{ }^{\circ} \mathrm{C}$. The bactericidal activity of the polymers was estimated by calculating the decrease in the number of bacteria, according to Equation 2.

\section{Results and Discussion}

The porosity degree and swelling properties of the polymer support influence the process of reagent diffusion and consequently the extent of modification reactions for introducing the biocidal groups in this matrix, as well as the accessibility of those introduced groups by bacteria or the diffusion of the biocidal agent in the medium. In order to establish the relationship between morphology characteristics of the copolymers supports, the functionalization degree of the copolymers and biocidal activity of the final products were employed two 2-Vpy-Sty-DVB copolymers with varied morphological structures. To prepare two copolymers with different type of porous structures, the copolymerization of $2 \mathrm{Vpy}$, Sty and DVB was carried out using mixtures of toluene and n-heptane. These two solvents are solvating and non-solvating respectively for polystyrene chains ${ }^{[23]}$. The principal morphological characteristics of these materials are summarized below ${ }^{[19]}$.

The C30Hep copolymer, synthesized with $30 \%$ n-heptane in the diluent mixture, had very low surface area and the fixed pore volume was not measurable (Table 1), indicating that this material has lower porosity (gel-like structure). In contrast, the C50Hep copolymer, synthesized with 50\% n-heptane, presented higher surface area and fixed pore volume, associated with lower apparent density, demonstrating that increasing the n-heptane proportion led to formation of a more porous structure. These data are confirmed by the electron micrographs of the internal structure these two copolymers (Figure 1). It can be seen that the $\mathrm{C} 30 \mathrm{Hep}$ copolymer has a homogeneous surface characteristic of gel materials. Conversely, the electron microscopy of the $\mathrm{C} 50 \mathrm{Hep}$ copolymer reveals the existence of channels between the microspheres aggregates, indicating the presence of pores.

According to Hildebrand solubility parameter theory ${ }^{[14,23]}$. when the difference between the solubility parameter $\left|\delta_{1}-\delta_{2}\right|$ of the polymer and solvent is low $\left(\left|\delta_{1}-\delta_{2}\right| \leq 1.5\right)$, the solvent may be considered a good solvent (solvating solvent) for the polymer. On the other hand, when this difference is high $\left(\left|\delta_{1}-\delta_{2}\right| \geq 1.5\right)$, the solvent can be considered a thermodynamic bad solvent for the polymer. Methanol is not a good solvent for Sty-DVB copolymers and these copolymers do not swell in methanol, because the difference between the solubility parameters of this solvent and Sty-DVB copolymer $\left|\delta_{1}-\delta_{2}\right|$ is high (Table 2). Nevertheless, the 2Vpy-Sty-DVB copolymers swelled in methanol (Table 1). This can be explained by considering that $2 \mathrm{Vpy}-\mathrm{Sty}-\mathrm{DVB}$ copolymers contain $70 \% 2 \mathrm{Vpy}$. The difference between the solubility parameters of methanol and poly-2-vinylpiridine is lower than the difference between the

Table 1. Physical characteristics of 2 Vpy-Sty-DVB copolymers ${ }^{[19]}$

\begin{tabular}{ccccc}
\hline Copolymers & $\begin{array}{c}\mathbf{d}_{\text {ap }}{ }^{\mathbf{a}} \\
\left(\mathbf{g ~ c m}^{-3}\right)\end{array}$ & $\begin{array}{c}\mathbf{S}^{\mathbf{b}} \\
\left(\mathbf{m}^{\mathbf{2}} \mathbf{g}^{-\mathbf{1}}\right)\end{array}$ & $\begin{array}{c}\mathbf{S D}_{\mathbf{M}}{ }^{\mathbf{c}} \\
(\boldsymbol{\%})\end{array}$ & $\begin{array}{c}\mathbf{S D}_{\mathbf{w}}{ }^{\mathbf{f}} \\
(\boldsymbol{\%})\end{array}$ \\
\hline C30Hep & 0.7 & 0.1 & 120 & 10 \\
C50Hep & 0.4 & 40.4 & 33 & 0 \\
\hline
\end{tabular}

a) apparent density; b) specific surface area (BET method); c) swelling degree in methanol; d) swelling degree in water C30Hep: 2Vpy-StyDVB copolymer synthesized with $30 \%$ of n-heptane; C50Hep: 2 VpySty-DVB copolymer synthesized with $30 \%$ of n-heptane

Table 2. Hildebrand Solubility Parameter of toluene, n-heptane, methanol, poly-2-vinylpiridine and Poly(Sty-DVB ${ }^{[24,26]}$

\begin{tabular}{|c|c|c|c|}
\hline & $\begin{array}{c}\delta_{1}{ }^{\mathrm{b}} \\
\left(\mathrm{MPa}^{1 / 2}\right)\end{array}$ & $\begin{array}{c}\delta_{2}{ }^{\mathrm{c}} \\
\left(\mathrm{MPa}^{1 / 2}\right)\end{array}$ & $\left|\delta_{1}-\delta_{2}\right|^{d}$ \\
\hline Toluene & 18.2 & & $0.4^{\mathrm{e}}$ \\
\hline n-Heptane & 15.1 & & $2.1^{\mathrm{f}}$ \\
\hline Methanol & 29.7 & & $11.9^{\mathrm{g}} 2.5^{\mathrm{h}}$ \\
\hline
\end{tabular}

Poly-2-vinylpiridine

27.2

Poly(Sty-DVB) ${ }^{a}$

17.8

a) Styrene-divinylbenzene copolymer with $20 \%$ of DVB; b) solubility parameter of the solvents; c) solubility parameter of the polymers; d) solubility parameters difference; e) $\left|\delta_{1}-\delta_{2}\right|$ between toluene and Poly(Sty-DVB); f) $\left|\delta_{1}-\delta_{2}\right|$ between n-heptane and Poly(Sty-DVB); g) $\left|\delta_{1}-\delta_{2}\right|$ between methanol and Poly(Sty-DVB); h) $\left|\delta_{1}-\delta_{2}\right|$ between methanol and Poly-2-vinylpiridine

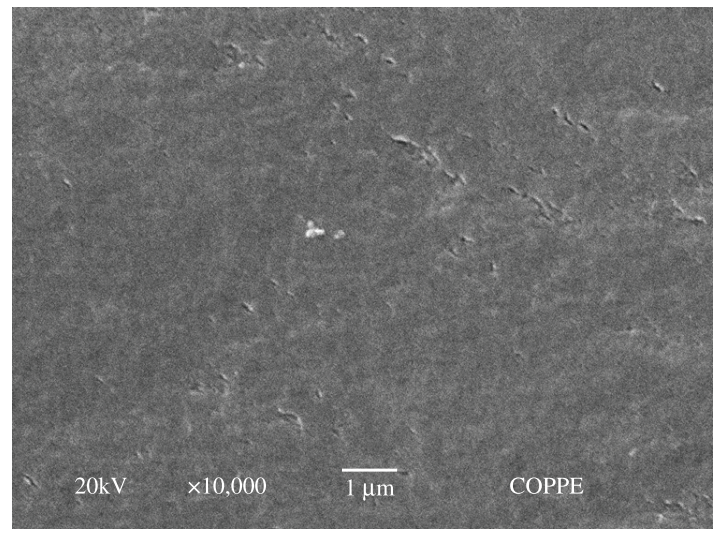

(a)

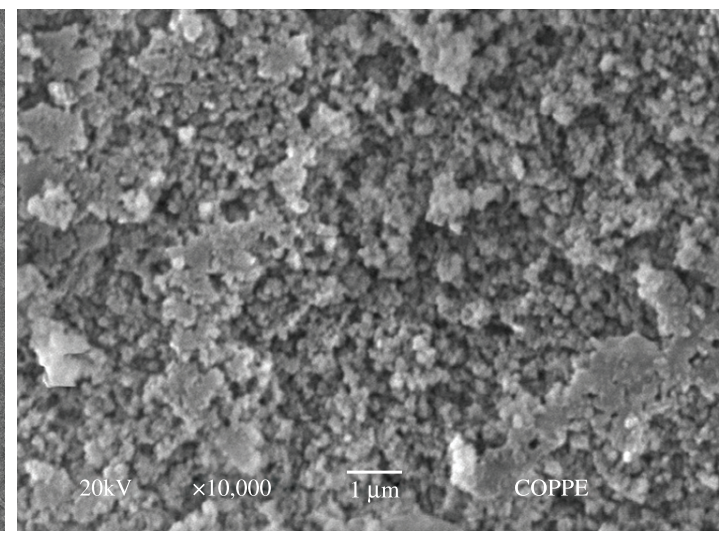

(b)

Figure 1. Electron micrographs of the internal structure of C30Hep (a) and C50Hep copolymers (b). 
solubility parameters of this solvent and Poly(Sty-DVB). Probably the difference between the solubility parameters of methanol and 2 Vpy-Sty-DVB copolymers is also low, making methanol a better solvent for 2Vy-Sty-DVB copolymers.

It was possible to observe that the swelling degree in methanol was markedly influenced by the diluent mixture composition used in the copolymer synthesis (Table 1). The C30Hep copolymer presented a higher swelling percentage in methanol than the C50Hep copolymer. The swelling capacity of the copolymers can be attributed to the expansion of collapsed polymer structures ${ }^{[17]}$ Since the $\mathrm{C} 50 \mathrm{Hep}$ copolymer is more porous, this material has a lower content of collapsed mass (gel phase).

The presence of absorption bands at $747 \mathrm{~cm}^{-1}$ due to C-H out-ofplane vibration of 2-substituted pyridine and bands of the $\mathrm{C}-\mathrm{N}$ ring stretching between 1600 and $1430 \mathrm{~cm}^{-1}$ on FTIR spectra of $2 \mathrm{Vpy}-$ Sty-DVB copolymer (represented on our other work ${ }^{[19]}$ ) were used as a qualitative indication of the presence of $2 \mathrm{Vpy}$ monomer on copolymer networks. It was possible to verify that the polymerization reaction occurred with high yields and the incorporation degree of 2 Vpy on copolymers was around $99 \%{ }^{[19]}$.

The C30Hep and C50Hep copolymers were reacted with methyl iodine and acrylonitrile in order to introduce quaternary ammonium groups into the polymeric matrix (Figure 2 ). The copolymers reacted with methyl iodine were designated C30Hep-MI and C50Hep-MI and the copolymers reacted with acrylonitrile were designated C30Hep-A and C50Hep-A, respectively. Evidence of the presence of those quaternary ammonium groups grafted on polymer supports is indicated by FTIR spectroscopy. The spectra of the copolymers reacted with methyl iodine showed a new absorption at $1628 \mathrm{~cm}^{-1}$, attributed to the formation of the respective pyridinium ion, as well as a change in the intensity of the absorptions, at $750 \mathrm{~cm}^{-1}$ (out of plane $\mathrm{C}-\mathrm{H}$ vibration of the pyridinium ring) due to the charge reduction of the nitrogen atoms, and a broad absorption at $3400 \mathrm{~cm}^{-1}$ involving $\mathrm{OH}$ association, as can be observed in our previous work ${ }^{[19]}$. The spectra of quaternized copolymers with acrylonitrile (represented on Figure 3) presented a new band at $2243 \mathrm{~cm}^{-1}$, attributed to $\mathrm{CN}$ group stretching ${ }^{[24]}$.

The quaternization with methyl iodine was also verified by thermoanalysis data ${ }^{[19]}$. The unmodified 2 Vpy-Sty-DVB copolymers degradation curves show only one significant weight loss step, around $350{ }^{\circ} \mathrm{C}$, and a single DTG peak, related to the decomposition of the main chain of the $2 \mathrm{Vpy}$-Sty-DVB copolymer. However, after reaction with methyl iodine, the thermal degradation curves of these copolymers presented two degradation steps (at $150{ }^{\circ} \mathrm{C}$ and $375^{\circ} \mathrm{C}$ ) and two DGT peaks, related to those weight-loss stages. The first thermal decomposition step can be related to the decomposition of methyl iodine groups attached to $2 \mathrm{Vpy}-\mathrm{Sty}-\mathrm{DVB}$ copolymers and the second thermal decomposition step at $400{ }^{\circ} \mathrm{C}$ to the degradation of the carbon chains of the copolymers. These TG and DTG curves has been published previously ${ }^{[19]}$.

The quaternization with acrylonitrile was quantified by elemental analysis. The nitrogen concentrations of the $\mathrm{C} 30 \mathrm{Hep}$ and $\mathrm{C} 50 \mathrm{Hep}$ copolymers were both equal to $6.37 \mathrm{mmol} \mathrm{g}^{-1}$. After reaction with acrylonitrile, the nitrogen levels of these two copolymers was found to be around $7.8 \mathrm{mmol} \mathrm{g}^{-1}\left(7.82 \mathrm{mmol} \mathrm{g}^{-1}\right.$ for C30Hep-A and $7.9 \mathrm{mmol} \mathrm{g}^{-1}$ for C50Hep-A). This means that the quaternization efficiency was around $22 \%$. The TG curves of these copolymers after reaction with acrylonitrile (Figure 4) also showed two degradation stages. However, the proximity between the DTG curves and the lower intensity of the DTG curve relative to the first degradation can indicate that the decomposition of the carbon chains of the acrylonitrile groups and polymer matrix occurred simultaneously.

The unmodified and quaternized copolymers were impregnated with iodine using two different methods: solvent phase (i1) and vapor phase (i2) $)^{[7,8]}$. The formation of charge transfer complexes was indicated by a color change. After the reaction with iodine, all the materials became brown. The iodine incorporation was quantified by gravimetry. The iodine anchorage degrees in the different materials are presented in Figure 5.

It is possible to observe that all materials can be impregnated with iodine and the percentage of iodine incorporated did not vary according to the kind of pore structure and the impregnation method. This behavior is opposite to that verified by Jandrey et al. ${ }^{[8]}$. Those authors reported that the method of impregnation in the vapor phase was more efficient than that in liquid phase and the more porous copolymer was more significantly modified. In this work, the impregnation of the copolymers with iodine in liquid phase was done in methanol. As showed before, the $\mathrm{C} 30 \mathrm{Hep}$ copolymer, with lower porosity degree, presented higher swelling capacity in methanol. Thus, C30Hep should present a higher iodine incorporation degree in the liquid phase because of this swelling capacity in methanol. However, the $\mathrm{C} 30 \mathrm{Hep}$ and $\mathrm{C} 50 \mathrm{Hep}$ copolymers presented similar iodine degrees when this impregnation method was employed. The C50Hep copolymer should also show higher iodine incorporation degree in the vapor phase because the presence of pores favors the diffusion of iodine through the polymer matrix. Nevertheless, these two copolymers also presented similar iodine concentrations in this medium.

Pyridine reacts with iodine to form a stable molecular $n-\sigma$ complex ${ }^{[8,25]}$. Probably for the C30hep and C50Hep copolymers, the formation of $n-\sigma$ complexes was limited only to a thin layer on the surface of these materials in liquid and vapor phase. This can be explained by the fact that iodine has higher volume. The diffusion
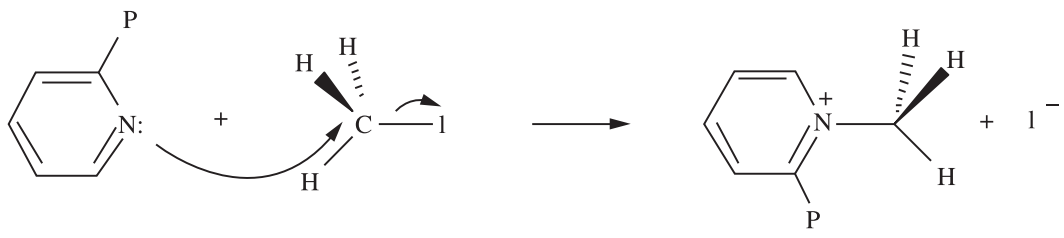

(a)
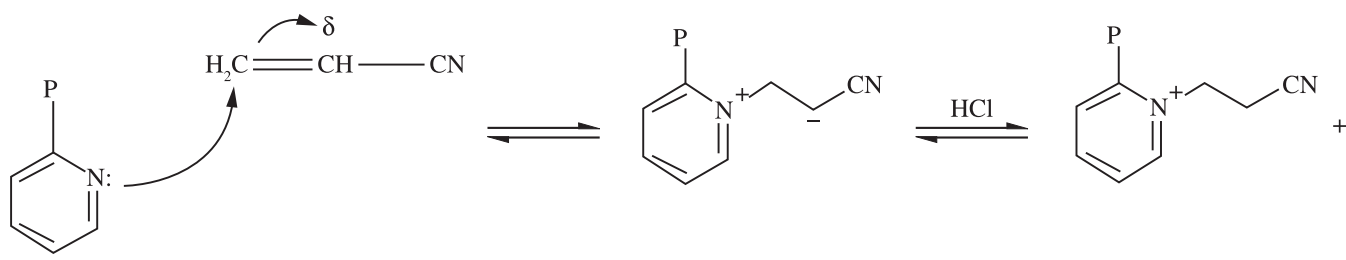

(b)

Figure 2. Quaternization reaction of 2Vpy-Sty-DVB copolymers with methyl iodine (a) and acrylonitrile (b). 

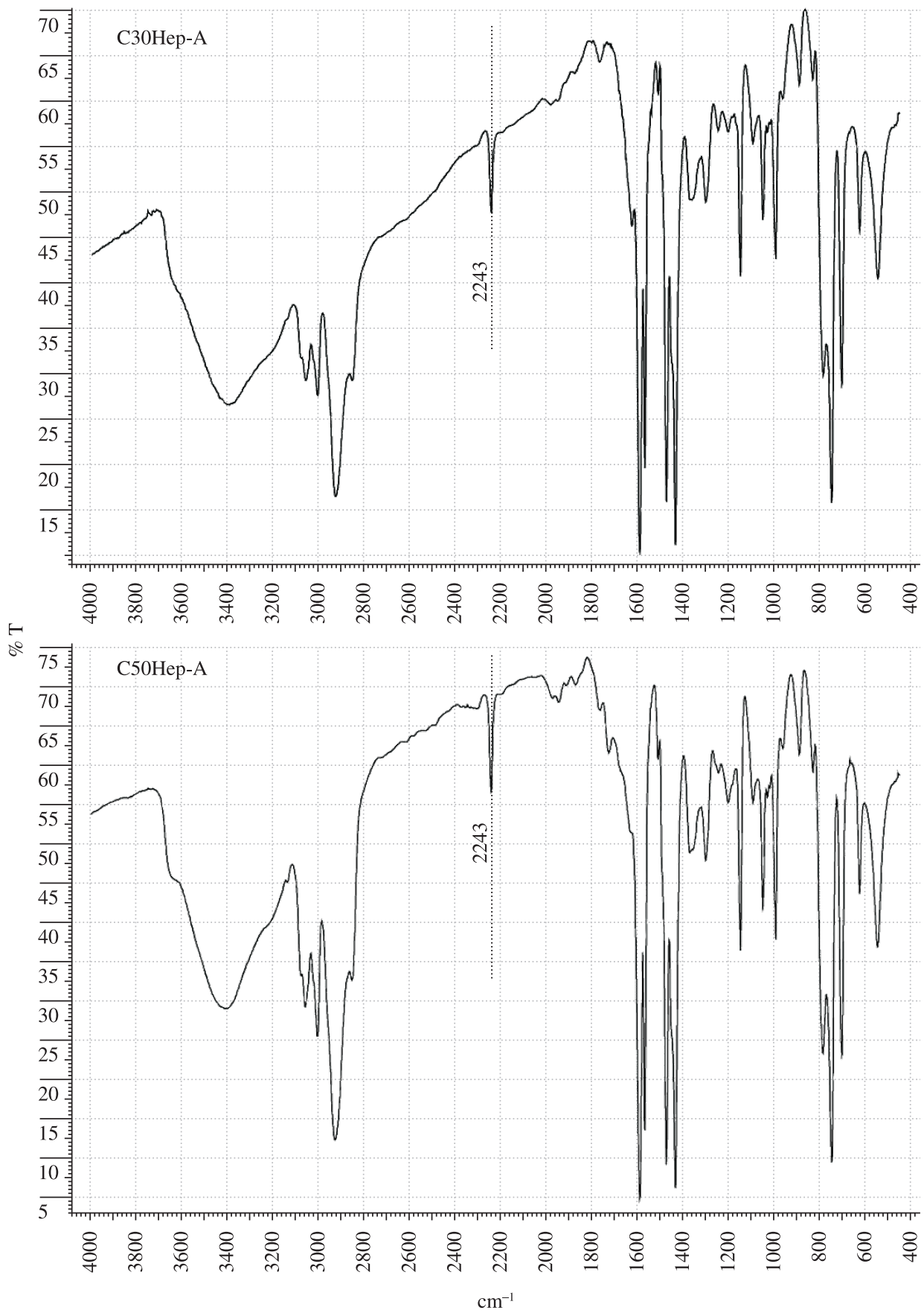

Figure 3. FTIR spectra of the C30Hep-A and C50Hep-A copolymers .

of iodine in the interior of the polymer matrix must have been much slower than the reaction with pyridine, even for the more porous copolymer, probably because this copolymer contains narrower pores. Thus, the formation of the complexes occurred before the iodine molecules had had time to penetrate into the copolymer. Consequently, the formation of charge transfer complexes was limited only to a thin layer on the surface of these materials, independent of the method of impregnation employed ${ }^{[26]}$.

The copolymers quaternized with methyl iodine were impregnated with iodine in a higher proportion than the unmodified ones. This indicates that the reaction favored the formation of charge transfer complexes between iodine and the quaternized nitrogen of the pyridine units. The copolymers quaternized with acrylonitrile presented iodine incorporation degrees similar to the unmodified materials. Maybe this was because the interaction between iodine and quaternized nitrogen was damaged by the longer carbon chain of the acrylonitrile. These results and the thermal analysis data for these two materials also suggest that the quaternization with methyl iodine occurred to a greater extent than the quaternization with acrylonitrile.

The swelling properties of the polymer support in water determine the accessibility of biocidal groups by bacteria or the diffusion of the biocidal agent in the aqueous medium. The copolymers swelling capacity in water was influenced by the composition of the diluent mixture used in their synthesis. The $\mathrm{C} 30 \mathrm{Hep}$ copolymer, synthesized with $30 \%$ n-heptane, had better swelling capacity in water than $\mathrm{C} 50 \mathrm{Hep}$, synthesized with $50 \%$ n-heptane, because of 


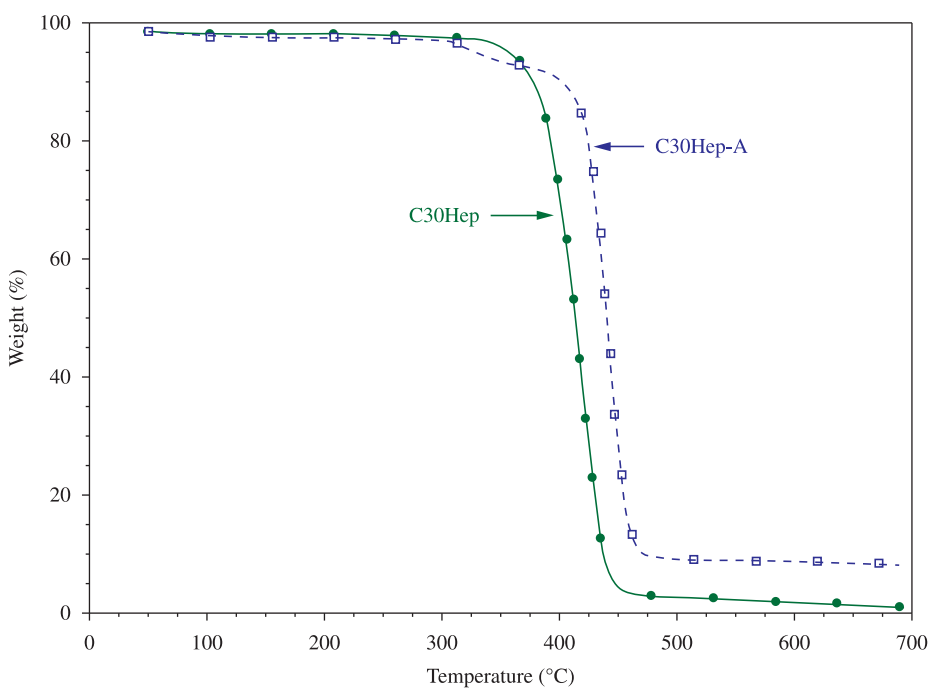

(a)

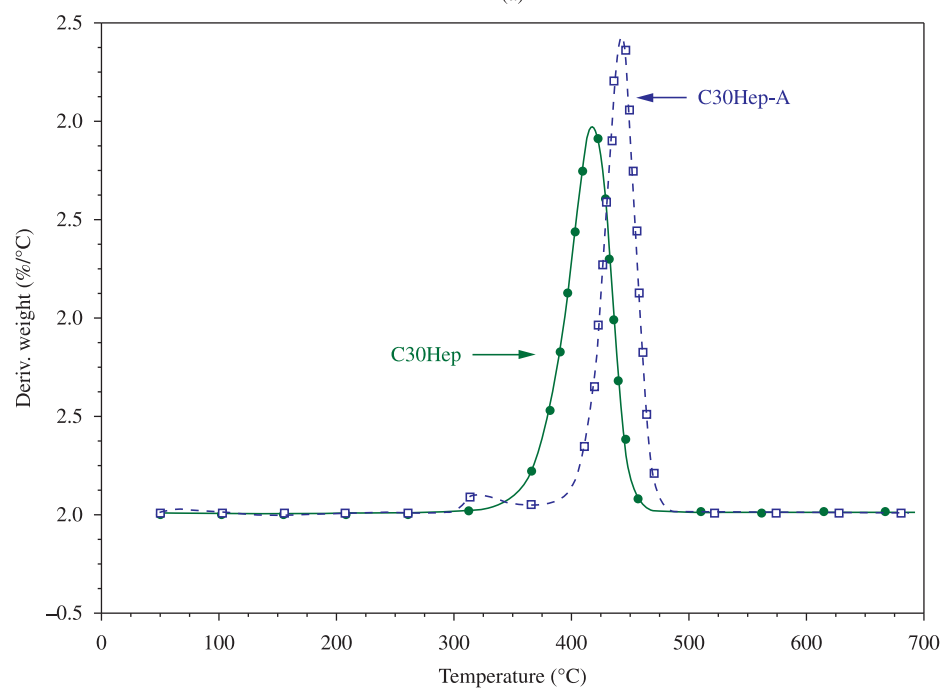

(b)

Figure 4. TG (a) and DTG (b) curves of the C30Hep and C30Hep-A copolymers.

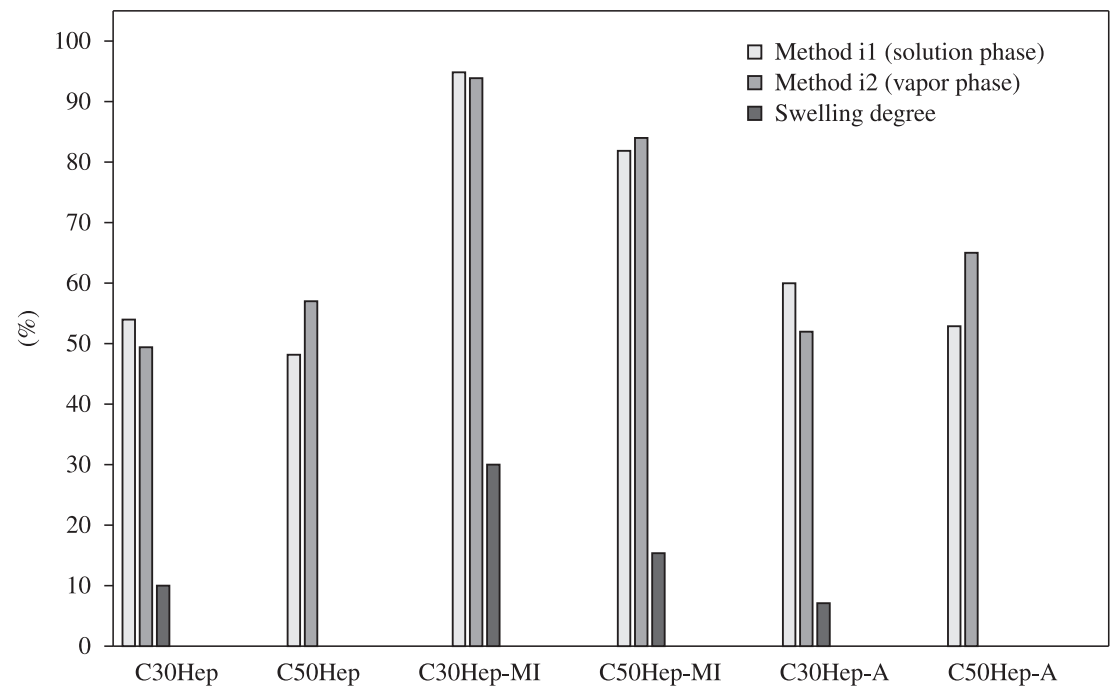

Figure 5. Iodine incorporation degree onto unmodified and quaternized copolymers ${ }^{[19]}$. C30Hep: 2 Vpy-Sty-DVB copolymer synthesized with $30 \%$ of n-heptane; C50 Hep: 2Vpy-Sty-DVB copolymer synthesized with 50\% of n-heptane; C30Hep-MI: copolymer C30Hep quaternized with methyl iodine; C50Hep-MI: copolymer C50Hep quaternized with methyl iodine; C30Hep-A: copolymer C30Hep quaternized with acrylonitrile; C50Hep-A: copolymer C50Hep quaternized with acrylonitrile. 
its higher content of collapsed mass (Figure 5). The 2Vpy-StyDVB copolymers quaternized with methyl iodine presented higher swelling capacity in water than the unmodified ones. On the other hand, the copolymers modified with acrylonitrile presented similar swelling capacity to the unmodified ones. This behavior confirms the results observed for the impregnation of those materials with iodine.

Figure 6 presents the antibacterial activity averages for the quaternized copolymers against E. Coli $(\mathrm{OHd} 5-\mathrm{K} 12)$ at varying concentrations ${ }^{[19]}$.

The unmodified copolymers did not present antibacterial activity against any concentration of $E$. Coli suspensions $(\mathrm{p}<0.05)$. The quaternization with methyl iodine and acrylonitrile increased the biocidal capacity of these two materials, but most of the quaternized copolymers did not have significant bactericidal action (antibacterial activity lower than $14 \%$ ) $^{[8]}$. The stability test results demonstrated that these four quaternized copolymers are contact disinfectants: there was no reduction in the number of $E$. Coli cells added to a saline solution eluted through columns containing quaternized copolymers. A comparison of the biocidal activity of the two quaternized copolymers showed that the $\mathrm{C} 30 \mathrm{Hep}$ copolymer quaternized with methyl iodine was more efficient. Although this copolymer is less porous (Table 1), its structure expands more in water (Figure 5), which permits some diffusion of the bacteria inside the copolymer and consequently increases their contact with the biocidal groups.

Table 3 presents the antibacterial activity averages of the C30Hep and $\mathrm{C} 50 \mathrm{Hep}$ copolymers and their derivatives quaternized and impregnated with iodine (charge transfer complexes).

Part of these data has already been published by our group ${ }^{[19]}$. As expected, the treatment of the unmodified and quaternized copolymers with iodine caused a considerable increase in antibacterial efficiency. In general, all the materials exhibited complete antibacterial activity in lower concentrations (until $10^{5}$ cells $\mathrm{mL}^{-1}$ ). The stability tests demonstrated that, unlike what was observed by Jandrey ${ }^{[7,8]}$, in general these impregnated copolymers are demand-release disinfectants. As mentioned in the introduction, a demand-release disinfectant is a material that releases the biocidal compound into the medium ${ }^{[4]}$. Thus, the copolymers impregnated with iodine probably released the iodine into the medium and this iodine was sufficient to kill concentrations up to $10^{5}$ cells $\mathrm{mL}^{-1}$.

Analysis of the antibacterial activity of the polymeric charge transfer complexes at higher cell concentrations showed that in a general the complexes prepared from copolymers quaternized with methyl iodine and acrylonitrile impregnated with iodine had better biocidal performance than the unmodified ones impregnated with iodine. Thus, as expected the quaternization reaction before impregnation with iodine enhances the biocidal capacity of the charge transfer complexes.

The charge transfer complexes derived from $\mathrm{C} 30 \mathrm{Hep}$ copolymer had better biocidal effect than the complexes derived from $\mathrm{C} 50 \mathrm{Hep}$ copolymer. Although $\mathrm{C} 30 \mathrm{Hep}$ copolymer had lower porosity, its swelling capacity in water was higher, which may have favored the diffusion of the iodine in the medium.

Analysis of the stability tests results shows that the charge transfer complexes derived from $\mathrm{C} 50 \mathrm{Hep}$ copolymer quaternized with acrylonitrile and impregnated with iodine in liquid and vapor phase (C50HEP-A-i1 and C50HEP-A-i2) are contact disinfectants, unlike most iodine-impregnated materials. The $\mathrm{C} 50 \mathrm{Hep}$ copolymer presented reduced swelling capacity in water and according to the nitrogen content results, the percentage of quaternization with acrylonitrile was also low (22\%). It is possible to suppose that the association between low swelling capacity in water and low quaternization degree with acrylonitrile originated materials did not liberate iodine in the medium sufficient to kill E. Coli $10^{4}$ cells $\mathrm{mL}^{-1}$ These two materials also exhibited lower antibacterial activity at higher cell concentrations in columns tests $\left(10^{6}\right.$ and $10^{7}$ cells $\left.\mathrm{mL}^{-1}\right)$, which confirms their reduced antibacterial activity.

In general, the polymers presented similar antibacterial activity, independent of the impregnation method employed, corroborating the data on iodine content and swelling degrees presented in Figure 5 .

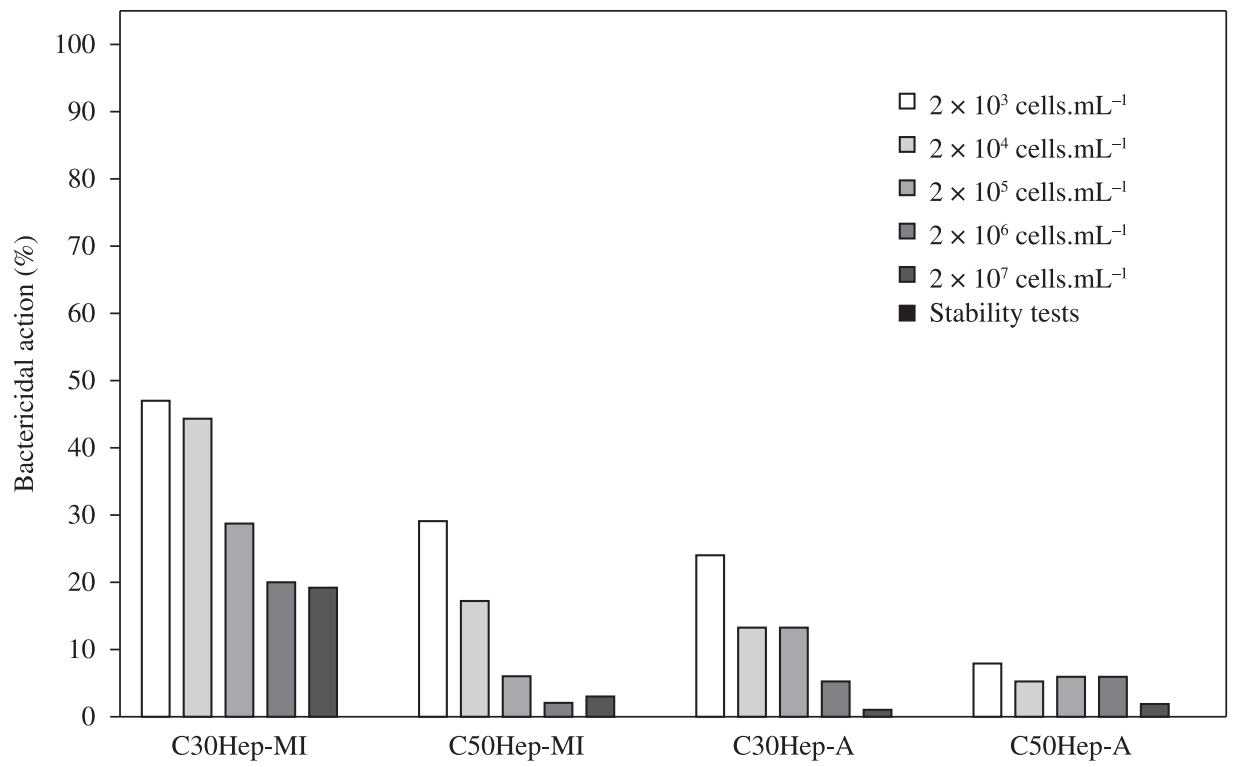

Figure 6. Antibacterial activity of 2 Vy-Sty-DVB copolymers quaternized with methyl iodine and acrylonitrile against Escherichia Coli suspensions ${ }^{[19]}$. Standard deviation $=5 \%$ CFUs; antibacterial activity $>14 \%$ (significant action, $p<0.05$ ); Initial concentration of cells $210^{-3}$ cells $\mathrm{mL}^{-1}$; $\mathrm{C}_{30 \mathrm{Hep}} \mathrm{MI}$ : copolymer C30Hep quaternized with methyl iodine; C50Hep-MI: copolymer C50Hep quaternized with methyl iodine; C30Hep-A: copolymer C30Hep quaternized with acrylonitrile; C50Hep-A: copolymer C50Hep quaternized with acrylonitrile. 


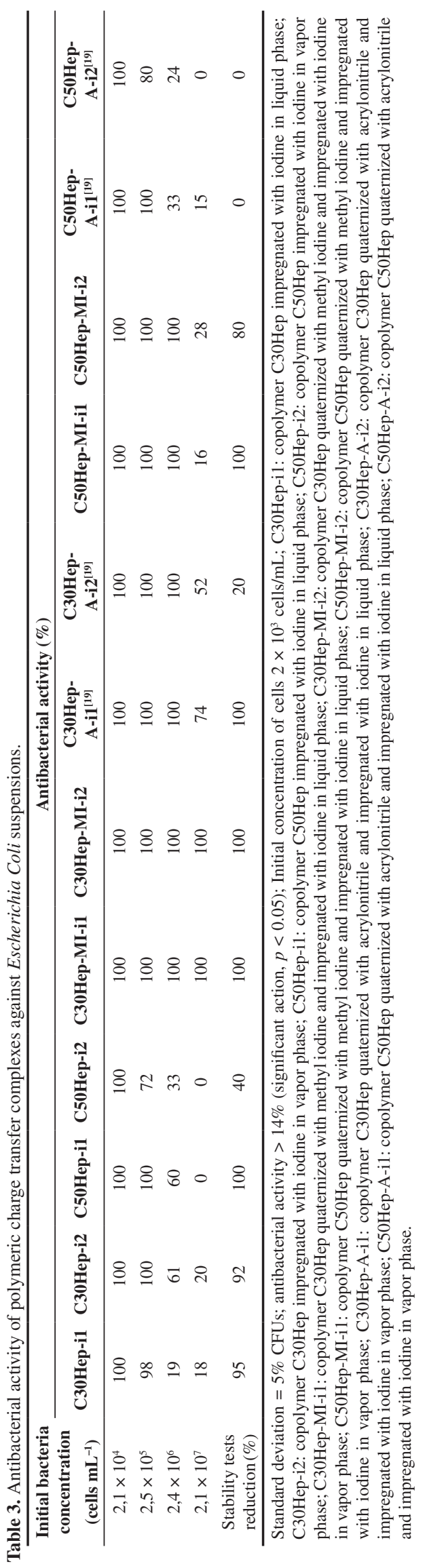




\section{Conclusions}

Two 2Vpy-Sty-DVB copolymers with varied porosity degrees were prepared using mixtures of toluene and n-heptane in different proportions. The increase of the $n$-heptane proportion in the diluent mixture caused an increase in porosity degree of the copolymers. These materials were successfully quaternized with methyl iodine and acrylonitrile and impregnated with iodine. The unmodified copolymers did not present antibacterial activity against E. Coli suspensions at any concentration. Quaternization with methyl iodine and acrylonitrile increased the biocidal performance of these two materials, but only the copolymer with lowest porosity degree modified with methyl iodine (C30Hep-MI) showed significant bactericidal action for all E. Coli concentrations. The 2Vpy-StyDVB copolymers quaternized and impregnated with iodine had higher antibacterial activity than the impregnated ones. Thus, the quaternization reaction of vinylpiridine units before the impregnation reaction enhances the biocidal capacity of charge transfer complexes with iodine. Based on the bacterial efficiency results, we can conclude that the charge transfer complexes derived from copolymer with lowest porosity degree and with highest swelling capacity in water (C30Hep) produced the most efficient materials. Based on these results, we can suggest that charge transfer complexes prepared from 2 Vpy copolymers with low porosity degree and quaternized with methyl iodine can be used to treat water contaminated with high $E$. Coli concentrations.

\section{Acknowledgements}

We thank the Fundação Coordenação de Aperfeiçoamento de Pessoal de Nível Superior (PRODOC/CAPES) and Fundação de Amparo a Pesquisa do Estado do Rio de Janeiro (FAPERJ) for financial support. We also express our thanks to the companies Petroflex, Nitriflex and Metacril for donating the reagents.

\section{References}

1. Hu, F. X.; Neoh, K. G.; Cen, L. \& Kang, E. T. - Biotechnol. Bioeng., 89, p.474 (2005). http://dx.doi.org/10.1002/bit.20384

2. Jiang, S.; Wang, L.; Yu, H. \& Chen, Y. - React. Funct. Polym., 62, p. 209 (2005). http://dx.doi.org/10.1016/j.reactfunctpolym.2004.11.002

3. Cheng, Z.; Zhu, X.; Shi, Z. L.; Neoh, K. G. \& Kang, E. T. - Ind. Eng. Chem. Res., 44, p.7098 (2005). http://dx.doi.org/10.1021/ie050225o

4. Iconomopoulou, S. M.; Andreopoulou, A. K.; Soto, A.; Kallitsis, J. K. \& Voyiatzis, G. A. - J. Control. Rel., 102, p.223 (2005). http://dx.doi. org/10.1016/j.jconrel.2004.10.006

5. Gelman, M. A.; Weisblum, B.; Lynn, D. M. \& Gellman, S. H. - Org. Let., 6, p.557, (2004). http://dx.doi.org/10.1021/o1036341+

6. Chen, Y.; Worley, S. D.; Huang, T. S.; Weese, J.; Kim, J.; Wey, C.I. \& Williams, J. F. - J. Appl. Polym. Sci., 92, p.368 (2004). http://dx.doi. org/10.1002/app.20038

7. Jandrey, A. C.; Santa Maria, L. C.; Aguiar, A. P.; Aguiar, M. R. M. P.; Mazzei, J. L. \& Felzenszwalb, I. - J. Appl. Polym. Sci., 93, p.972 (2004). http://dx.doi.org/10.1002/app.20523
8. Jandrey, A. C.; Aguiar, A. P.; Aguiar, M. R. M. P.; Santa Maria, L. C.; Mazzei, J. L. \& Felzenszwalb, I. - Eur. Polym. J., 43, p.4712 (2007). http://dx.doi.org/10.1016/j.eurpolymj.2007.07.042

9. Kenawy, E. R.; Worley, S. D. \& Broughton, R. - Biomacromolecules, 8 , p.1359 (2007). http://dx.doi.org/10.1021/bm061150q

10. Adelmann, R.; Mennicken, M.; Popescu, D.; Heine, E.; Keul, H. \& Moeller, M. - Eur. Polym. J., 45, p.3093 (2009). http://dx.doi. org/10.1016/j.eurpolymj.2009.08.013

11. Barnes, K.; Liang, J.; Wu, R.; Worley, S. D.; Lee, J.; Broughton, R. M. \& Huang, T. S. - Biomaterials, 27, p.4825 (2006). http://dx.doi. org/10.1016/j.biomaterials.2006.05.023

12. Ahmed, A. E. I.; Hay, J. N.; Bushell, M. E.; Wardell, J. N. \& Cavalli, G. - React. Funct. Polym., 68, p.248 (2008). http://dx.doi.org/10.1016/j. reactfunctpolym.2007.09.004

13. Ahmed, A. E. I.; Hay, J. N.; Bushell, M. E.; Wardell, J. N. \& Cavalli, G. - React. Funct. Polym., 68, p.1448 (2008). http://dx.doi. org/10.1016/j.reactfunctpolym.2008.06.021

14. Coutinho, F. M. B.; Rezende, S. M. \& Barbosa, C. C. R. - React. Funct. Polym., 49, p.235 (2001). http://dx.doi.org/10.1016/S13815148(01)00079-7

15. Coutinho, F. M. B.; Souza, R. R. \& Gomes, A. S. - Eur. Polym. J., 40, p.1525 (2004). http://dx.doi.org/10.1016/j.eurpolymj.2004.02.003

16. Teixeira, V. G.; Coutinho, F. M. B.; Petrocínio, F. R. M. \& Gomes, A. S. - J. Braz. Chem. Soc., 16, p.951 (2005). http://dx.doi.org/10.1590/ S0103-50532005000600010

17. Cunha, L.; Coutinho, F. M. B.; Teixeira, V. G.; De Jesus, E. F. O. \& Gomes, A. S. - Polym. Bull., 61, p.319, (2008). http://dx.doi. org/10.1007/s00289-008-0962-2

18. Costa, L. C.; Gomes, A. S.; Coutinho, F. M. B. \& Teixeira, V. G. - React. Funct. Polym., 70, p.738 (2010). http://dx.doi.org/10.1016/j. reactfunctpolym.2010.07.003

19. Valle, A. S. S.; Costa, L. C.; Marques, M. R. C.; Silva, C. L. P.; Santa Maria, L. C.; Merçon, F. \& Aguiar, A. P. - Quim. Nova, 34, p.577 (2011).

20. Rodrigues, A. S. S.; Aguiar, A. P.; Aguiar, M. R. M. P. \& Santa Maria, L. C. - J. Braz. Chem. Soc., 18, p.431 (2007). http://dx.doi.org/10.1590/ S0100-40422011000400005

21. American Society for Testing and Materials - "ASTM D 1895-69", Annual Book of ASTM Philadelphia (1975).

22. Furtado Filho, A. A. M. \& Gomes, A. S. - Polym. Bull., 57, p.415, (2006). http://dx.doi.org/10.1007/s00289-006-0574-7

23. Grulke, E. A. - "Solubility parameter values", in: Polymer Handbook, Brandrup, J.; Immergut, E. H.; Grulke, E. A. (ed.), p. 675-714, John Wiley \& Sons Inc., New Jersey (1999).

24. Colthup, N. B.; Daly, L. H. \& Wiberley, S. E. - "Introduction to infrared and raman spectroscopy", Academic Press, New York and London (1964).

25. Stankovic, R. I.; Lenzs, R. W. \& Karasz, F. E. - Eur. Polym. J., 26, p.359 (1990)

26. Chakrabarti, A. \& Sharma, M. M. - React. Polym., p.20 (1993).

Received: 16/01/12

Revised: $19 / 07 / 12$

Accepted: 13/08/12 